\title{
ANALISIS STRATEGI BISNIS DALAM UPAYA MENINGKATKAN PENJUALAN PADA LOVE SHOP BOUTIQUE DI BANDAR LAMPUNG
}

\section{ANALYSIS OF BUSINESS STRATEGIES IN AN EFFORT TO INCREASE SALES AT THE LOVE SHOP BOUTIQUE}

\author{
Hendri Dunan \\ Dosen Fakultas Ekonomi dan Bisnis Universitas Bandar Lampung \\ Jln. Z. A. Pagar Alam No. 26 Labuhan Ratu, Bandar Lampung 35142. \\ email: hendri.dunan@ubl.ac.id \\ Habiburrahman \\ Dosen Fakultas Ekonomi dan Bisnis Universitas Bandar Lampung \\ Jln. Z. A. Pagar Alam No. 26 Labuhan Ratu, Bandar Lampung 35142. \\ email: habiburrahman@ubl.ac.id \\ Berka Angestu \\ Alumni Fakultas Ekonomi dan Bisnis Universitas Bandar Lampung \\ email : berka.16011188@student.ubl.ac.id
}

\begin{abstract}
This study aims to determine the Business Strategies applied in an effort to increase sales is appropriate. The research method used is a descriptive qualitative research method. The data used in this study are primary and secondary data. data collection techniques through observation, interviews, documentation and questionnaire distribution at the Love Shop Boutique. Analysis of the data used in this study is a SWOT (Strength, Weakness, Opportunity and Threat) analysis. The results of this study indicate that an effective strategy based on SWOT Matrix Analysis and SWOT Cartesian diagram produced an SO (Strength-Opportunity) strategy which has the highest score of 4.96 and is in quadrant 1 (Growth Oriented Strategy).
\end{abstract}

Keywords: Business Strategy, SWOT, Sales

\begin{abstract}
ABSTRAK
Penelitian ini bertujuan untuk mengetahui Strategi Bisnis yang diterapkan dalam upaya meningkatkan penjualan sudah tepat. Metode penelitian yang digunakan adalah metode penelitian deskriptif kualitatif. Data yang digunakan dalam penelitian ini adalah data primer dan skunder. Teknik pengumpulan data melalui observasi, wawancara, dokumentasi dan penyebaran kuisioner pada Love Shop Boutique. Analisis data yang digunakan pada penelitian ini adalah analisis SWOT (Strength, Weakness, Opportunity and Threat). Dari hasil penelitian ini menunjukkan bahwa strategi yang efektif berdasarkan Analisis Matriks SWOT dan diagram cartesius SWOT dihasilkan strategi SO (Strength- Opportunity) mempunyai skor nilai tertinggi yaitu 4,96 dan berada pada kuadran 1 (Growth Oriented Strategy).
\end{abstract}

Kata Kunci : Strategi Bisnis, SWOT, Penjualan 


\section{PENDAHULUAN}

Persaingan bisnis dalam era globalisasi dewasa ini sangat ketat, di mana setiap perusahaan dituntut untuk dapat memenuhi kebutuhan konsumen serta berusaha untuk menciptakan suatu produk yang mempunyai keunggulan dan menciptakan produk yang berbeda dengan pesaing. Dengan demikian usaha pengembangan produk yang berbeda, dapat menjadi suatu strategi yang efektif bagi perusahaan dalam memberikan penawaran produk yang inovatif sehingga tercapai suatu kepuasan masing-masing pihak, baik dari pembeli karena membeli produk yang sesuai dengan kebutuhannya dan seleranya maupun bagi pihak perusahaan yang ingin mendapatkan keuntungan dari penjualan produkproduknya dan juga menjaga citra baik perusahaan di mata konsumen.

Berdasarkan masalah diatas maka tujuan penelitian ini adalah sebagai berikut : untuk mengetahui Strategi Bisnis yang diterapkan dalam upaya meningkatkan penjualan sudah tepat.

\section{TINJAUAN PUSTAKA}

Menurut David (2013) : "Manajemen strategi dapat didefinisikan sebagai seni dan ilmu untuk memformulasi, mengimplementasi, dan mengevaluasi keputusan lintas fungsi memungkinkan organisasi dapat mencapai tujuannya". Menurut Stephen P.Robbins-Mary Coulter (2014) : "Manajemen strategi adalah apa yang manajer lakukan untuk mengembangkan strategi organisasi. Ini adalah tugas penting yang melibatkan semua fungsi manajemen dasar

perencanaan, pengorganisasian, memimpin, dan pengendalian". Rivai dan Darsono (2015) : "Strategi ialah cara dan alat yang digunakan untuk mencapai tujuan akhir (sasaran atau objektif). Strategi harus mampu membuat semua bagian dari suatu organisasi yang luas menjadi satu, terpadu untuk mencapai tujuan akhir (sasaran/objektif); ini adalah masalah kegiatan operasi organisasi”. Menurut Kasmir dan Jakfar (2012) : Bisnis adalah usaha yang dijalankan yang tujuan utamanya adalah keuntungan. Menurut Sudaryono (2015) : "Bisnis adalah aktivitas yang dilakukan seseorang atau sekelompok orang perusahaan dalam bentuk jasa atau barang untuk memperoleh laba". Joewono (2012) : "Strategi bisnis adalah strategi mencapai tujuan yang sering dianalogikan dengan strategi catur, yang dimana sistematika berfikir, penyusunan rencana, kesigapan melangkah, keberanian mengambil resiko dan gairah untuk memenangkan pertandingan merupakan beberapa karakteristik permainan catur yang relevan dengan praktek pengelolaan bisnis". Menurut Solihin (2012) : "Strategi bisnis berbeda dengan strategi pada level korporat. Strategi di level bisnis ini lebih menfokuskan untuk meningkatkan posisi bersaing produk atau jasa perusahaan di dalam segmen pasar tertentu". Rangkuti (2013) : "Analisis SWOT adalah identifikasi berbagai faktor secara sistematis untuk merumuskan strategi perusahaan. Analisis ini didasarkan pada logika yang dapat memaksimalkan kekuatan (Strength) dan peluang (Opportunities), namun secara bersamaan dapat meminimalkan kelemahan (Weakness) dan ancaman (Threats)". Menurut Freddy Rangkuti (2014) : "Analisis SWOT adalah suatu cara untuk mengidentifikasi berbagai faktor secara sistematis dalam rangka merumuskan strategi perusahaan. Analisis ini didasarkan pada logika 
dapat memaksimalkan kekuatan dan peluang, namun secara bersamaan dapat meminimalkan kelemahan dan ancaman". Menurut Thamrin Abdullah dan Francis Tantri (2016) : “ Penjualan adalah bagian dari promosi dan promosi adalah salah satu bagian dari keseluruhan sistem pemasaran". Menurut Basu Swastha dalam Irwan Sahaja (2014) : "Penjulan adalah suatu proses pertukaran barang atau jasa antara penjual dan pembeli".

\section{METODOLOGI PENELITIAN}

Jenis penelitian ini dilakukan dengan pendekatan Library Research / pustaka dan Field Research / penelitian lapangan (Habiburrahman, dkk., 2019). Adapun pengertian dari Library Research / pustaka dan Field Research / penelitian lapangan adalah sebagai berikut : Penelitian Kepustakaan (Library Research)yaitu pengumpulan data yang berasal dari bahanbahan perpustakan baik berupa buku buku, kamus, jurnal, dokumen, majalah, tulisan - tulisan ilmiah dan bacaan lainnya yang berhubungan dengan penelitian. Penelitian Lapangan (Field Research) Penelitian lapangan yaitu suatu penelitian yang dilakukan secara sistematis dengan melihat secara langsung objek atau data yang diteliti melalui kunjungan langsung melalui observasi, wawancara, dokumentasi dan kuisioner.

Desain penelitian merupakan kerangka kondisi pengumpulan dan analis data yang bertujuan untuk menjawab tujuan penelitian. Penelitian ini merupakan penelitian Deskriptif. Tujuan dari penelitian deskriptif ini adalah untuk membuat deskripsi, gambaran atau lukisan secara sistematis, faktual dan akurat mengenai fakta-fakta, sifat-sifat serta hubungan antar fenomena yang diselidiki.

\section{Teknik Pengumpulan Data}

Observasi penulis mengamati langsung ke pemilik Usaha Love Shop Boutique di Bandar Lampung untuk mendapatkan informasi yang dibutuhkan dan melakukan pencatatan terhadap data yang diperoleh. Wawancara penulis melakukan wawancara dengan pemilik Usaha Love Shop Boutique di Bandar Lampung dengan mengajukan pertanyaan yang berkaitan dengan strategi bisnis. Dokumentasi Teknik pengumpulan data yang dilakukan dengan menggunakan dokumen tertulis (hasil penelitian, laporan tertulis, buku literatur, majalah, jurnal dan lain sebagainya) sebagai sumber data penelitian dengan cara melakukan pengelompokan atau klarifikasi data yang berhubungan dengan masalah penelitian. Kuisioner Pengumpulan data factual untuk memperoleh data variabel, faktor penghambat (Habiburrahman,dkk., 2018) pada Usaha Love Shop Boutique di Bandar Lampung.

\section{Jenis Data dan Sumber Data}

Data Primer yaitu data yang diperoleh secara langsung dari objek penelitian dengan menggunakan alat pengambilan data langsung pada subjek sebagai sumber informasi yang dicari. Dalam penelitian ini, peneliti menyebarkan kuisioner yang berhubungan dengan subjek penelitian. Data Sekunder yaitu data yang diperoleh lewat pihak lain, tidak langsung diperoleh oleh peneliti dari objek penelitianya. Dalam penelitian ini, peneliti melakukan metode dari lapangan dan kepustakaan.

\section{Metode Analisis}

Metode analisis yang digunakan pada penelitian ini adalah metode analisis kualitatif. Data kualitatif adaalah data yang berbentuk kalimat, kata atau gambar (Riswan dan Hendri Dunan., 2019). Dengan metode penelitian ini yaitu metode deskriptif untuk melihat/menggambarkan bagaimana 
strategi bisnis yang diterapkan pada Love Shop Boutique.

\section{Analisis SWOT (Strenghts, Weakness, Opportunity and Threats)}

Metode kerja analisis SWOT guna menentukan kekuatan, kelemahan, peluang dan ancaman perusahaan adalah sebagai berikut : a. Mengisi daftar pertanyaan dengan memberikan tanda silang $(\sqrt{ })$ pada jawaban yang dianggap paling tepat.b .Setiap pertanyaan diberikan nilai menurut tingkat kepentingannya oleh pemilik berdasarkan kondisi lingkungannya baik internal maupun eksternal, dengan asumsi menggunakan skala likert (Freddy Rangkuti, 2016) : Kurang Penting, Cukup Penting, Penting, Sangat Penting c. Pada setiap kolom ditetapkan nilai antara lain: Kurang Penting =1, Cukup Penting =2 Penting $=3$, Sangat Penting $=4$,
d.Mengidentifikasikan faktor internal yang menjadi kekuatan dan kelemahan usaha Love Shop Boutique serta factor eksternal yang menjadi peluang dan ancaman usaha Love Shop Boutique. Setelah diketahui kekuatan, kelemahan, peluang dan ancaman usaha, kemudian dilanjutkan dengan mencari faktorfaktor strategi internal dan eksternal perusahaan.

\section{HASIL DAN PEMBAHASAN}

Berdasarkan Tabel 1 dan 2 hasil perbandingan unsur-unsur faktor internal dan eksternal Love Shop Boutique dengan usaha pesaing, maka dapat diketahui faktor-faktor internal yang menjadi kekuatan dan kelemahan serta faktor-faktor eksternal yang menjadi peluang dan ancaman Love Shop Boutique. Adapun tabel IFAS dan EFAS Love Shop Boutique dapat dilihat pada Tabel 3 dan 4

Tabel 1. Hasil Perbandingan Faktor Internal dengan Usaha Pesaing

\begin{tabular}{|c|c|c|c|}
\hline No. & Unsur-unsur Faktor & Nilai & Kekuatan/Kelemahan \\
\hline 1. & $\begin{array}{l}\text { Produk berpengaruh terhadap } \\
\text { pembelian konsumen }\end{array}$ & 2 & Kelemahan \\
\hline 2. & Persediaan produk cukup banyak & 3 & Kekuatan \\
\hline 3. & Kemudahan mendapatkan produk & 2 & Kelemahan \\
\hline 4. & Harga terjangkau & 2 & Kelemahan \\
\hline 5. & Penentuan harga produk & 4 & Kekuatan \\
\hline 6. & $\begin{array}{l}\text { Harga produk dibandingkan } \\
\text { pesaing }\end{array}$ & 3 & Kekuatan \\
\hline 7 & Lokasi usaha strategis & 2 & Kelemahan \\
\hline 8 & Keluhan pelanggan & 4 & Kekuatan \\
\hline 9 & Jumlah pekerja & 3 & Kekuatan \\
\hline 10 & Tingkat kepercayaan & 3 & Kekuatan \\
\hline 11 & Kemampuan pekerja & 4 & Kekuatan \\
\hline 12 & Manajemen keuangan & 4 & Kekuatan \\
\hline
\end{tabular}

Sumber : Data diolah, 2019 
Berdasarkan perhitungan pada Tabel 3 Internal Factor Analysis Summary (IFAS) diatas, diketahui faktor strenght mempunyai total nilai skor 2,72 sedangkan weakness mempunyai total nilai skor 0,48 . Adapun total nilai skor keseluruhan faktor internal (kekuatan dan kelemahan) adalah 3,2. Seperti halnya pada IFAS, maka pada faktorfaktor strategi eksternal juga dilakukan identifikasi yang hasilnya ada pada Tabel 4.

Tabel 2. Hasil Perbandingan Faktor Eksternal dengan Usaha Pesaing

\begin{tabular}{clcc}
\hline No. & \multicolumn{1}{c}{ Unsur - unsur Faktor } & Nilai & Peluang / Ancaman \\
\hline 1. & $\begin{array}{l}\text { Memperhatikan kemampuan } \\
\text { konsumen dalam membeli }\end{array}$ & 3 & Ancaman \\
2. & $\begin{array}{l}\text { Konsumen sering membeli } \\
\text { produk banyak }\end{array}$ & 3 & Peluang \\
3. & Memiliki pemasok tetap & 3 & Peluang \\
4. & Pengiriman pemasok terjadwal & 3 & Peluang \\
5. & Pengiriman bahan baku selalu & 1 & Ancaman \\
& tepat waktu & & \\
6. & Kualitas barang sesuai & 3 & Peluang \\
7. & Memiliki banyak pesaing & 2 & Peluang \\
8. & Merasa terganggu adanya pesaing & 2 & Ancaman \\
9. & Memiliki produk sama & 1 & Ancaman \\
10. & Harga yang ditawarkan pesaing. & 4 & Peluang \\
\hline
\end{tabular}

Sumber : Data diolah, 2019

Tabel 3. Internal Factor Analysis Summary (IFAS)

\begin{tabular}{|c|c|c|c|}
\hline Faktor-faktor Startegi Internal & Bobot & Rating & Nilai Skor \\
\hline \multicolumn{4}{|l|}{ Strenght (S) } \\
\hline 1. Persediaan produk cukup banyak & 0,08 & 3 & 0,24 \\
\hline 2. Penentuan harga produk & 0,11 & 4 & 0,44 \\
\hline $\begin{array}{l}\text { 3. Harga produk sama dengan } \\
\text { pesaing }\end{array}$ & 0,08 & 3 & 0,24 \\
\hline 4. Tidak ada keluhan pelanggan & 0,11 & 4 & 0,44 \\
\hline 5. Jumlah pekerja mencukupi & 0,08 & 3 & 0,24 \\
\hline 6. Tingkat kepercayaan & 0,08 & 3 & 0,24 \\
\hline 7. Kemampuan pekerja baik & 0,11 & 4 & 0,44 \\
\hline 8. Manajemen keuangan baik. & 0,11 & 4 & 0,44 \\
\hline Sub Total & 0,76 & 28 & 2,72 \\
\hline \multicolumn{4}{|l|}{ Weakness (W) } \\
\hline $\begin{array}{l}\text { 1. Produk cukup berpengaruh } \\
\text { terhadap pembelian konsumen }\end{array}$ & 0,06 & 2 & 0,12 \\
\hline $\begin{array}{l}\text { 2. Cukup mudah mendapatkan } \\
\text { produk }\end{array}$ & 0,06 & 2 & 0,12 \\
\hline 3. Harga cukup terjangkau & 0,06 & 2 & 0,12 \\
\hline 4. Lokasi kurang strategis & 0,06 & 2 & 0,12 \\
\hline Sub Total & 0,24 & 8 & 0,48 \\
\hline Total & 1,00 & 36 & 3,2 \\
\hline
\end{tabular}

Sumber : Data diolah, 2019 
Berdasarkan perhitungan pada Tabel 4 Eksternal Factor Analysis Summary (EFAS) di atas, diketahui faktor Opportunity mempunyai total nilai skor 2,24 dan Threat mempunyai total nilai skor 0,6 dan total nilai keseluruhan faktor eksternal (peluang dan ancaman) adalah 2,84. Selanjutnya nilai total skor masing-masing faktor dapat dirinci, strenght : 2,72, weakness :0,48, opportunity : 2,24 dan threath : 0,6. Sedangkan total nilai skor keseluruhan untuk faktor internal (kekuatan dan kelemahan) adalah : 3,2 dan faktor eksternal (peluang dan ancaman) adalah 2,84 .

Diagram cartesius analisis SWOT adalah tahap analisis selanjutnya setelah tabel IFAS dan EFAS dibuat. Berdasarkan tabel IFAS dan EFAS diketahui nilai Strength:2,72 di atas nilai
Weakness:0,48 dengan selisih: 2,24 dan nilai Opportunity: 2,24 nilai Threat: 0,6 dengan selisih 1,64 . Dari hasil identifikasi faktor-faktor tersebut maka dapat digambarkan dalam diagram cartesius analisis SWOT yang dapat dilihat pada gambar 1 .

Berdasarkan diagram cartesius analisis SWOT diatas, diketahui Love Shop Boutique berada dikuadran 1, dimana situasi yang sangat menguntungkan. Pada kuadran ini, Love Shop Boutique memiliki peluang dan kekuatan sehingga dapat memanfaatkan peluang yang ada. Strategi yang diterapkan dalam kondisi ini adalah mendukung kebijakan pertumbuhan yang agresif ( Growth Oriented Strategy ). Adapun analisis matrik SWOT dapat dilihat pada Tabel 4.6

Tabel 4. Eksternal Factor Analysis Summary (EFAS)

\begin{tabular}{lccc}
\hline \multicolumn{1}{c}{ Faktor-faktor Strategi Eksternal } & Bobot & Rating & $\begin{array}{c}\text { Nilai } \\
\text { Skor }\end{array}$ \\
\hline $\begin{array}{l}\text { Opportunity (O) } \\
\text { 1. Konsumen sering membeli }\end{array}$ & 0,12 & 3 & 0,36 \\
$\quad \begin{array}{l}\text { produk banyak } \\
\text { 2. Memiliki pemasok tetap }\end{array}$ & 0,12 & 3 & 0,36 \\
3. Pengiriman pemasok terjadwal & 0,12 & 3 & 0,36 \\
4. Kualitas barang sesuai & 0,12 & 3 & 0,36 \\
5. Memiliki banyak pesaing & 0,08 & 2 & 0,16 \\
6. Tidak terganggu dengan harga & 0,16 & 4 & 0,64 \\
$\quad$ yang ditawarkan pesaing & & & \\
\hline Sub Total & 0,72 & 18 & 2,24 \\
\hline Threat (T) & 0,12 & 3 & 0,36 \\
1. Kurang memperhatikan & & & \\
$\quad \begin{array}{l}\text { kemampuan konsumen dalam } \\
\quad \text { membeli }\end{array}$ & 0,04 & 1 & 0,04 \\
2. Pengiriman bahan baku tidak & & & \\
$\quad$ tepat waktu & 0,08 & 2 & 0,16 \\
3. Merasa terganggu adanya pesaing & 0,04 & 1 & 0,04 \\
4. Memiliki produk sama & & & 0,6 \\
\hline Sub Total & 0,28 & 7 & 2,84 \\
\hline Total & 1,00 & 25 & \\
\hline
\end{tabular}

Sumber : Data diolah, 2019 
Analisis Strategi... (Hendri D - Habiburrahman - Berka Angestu)

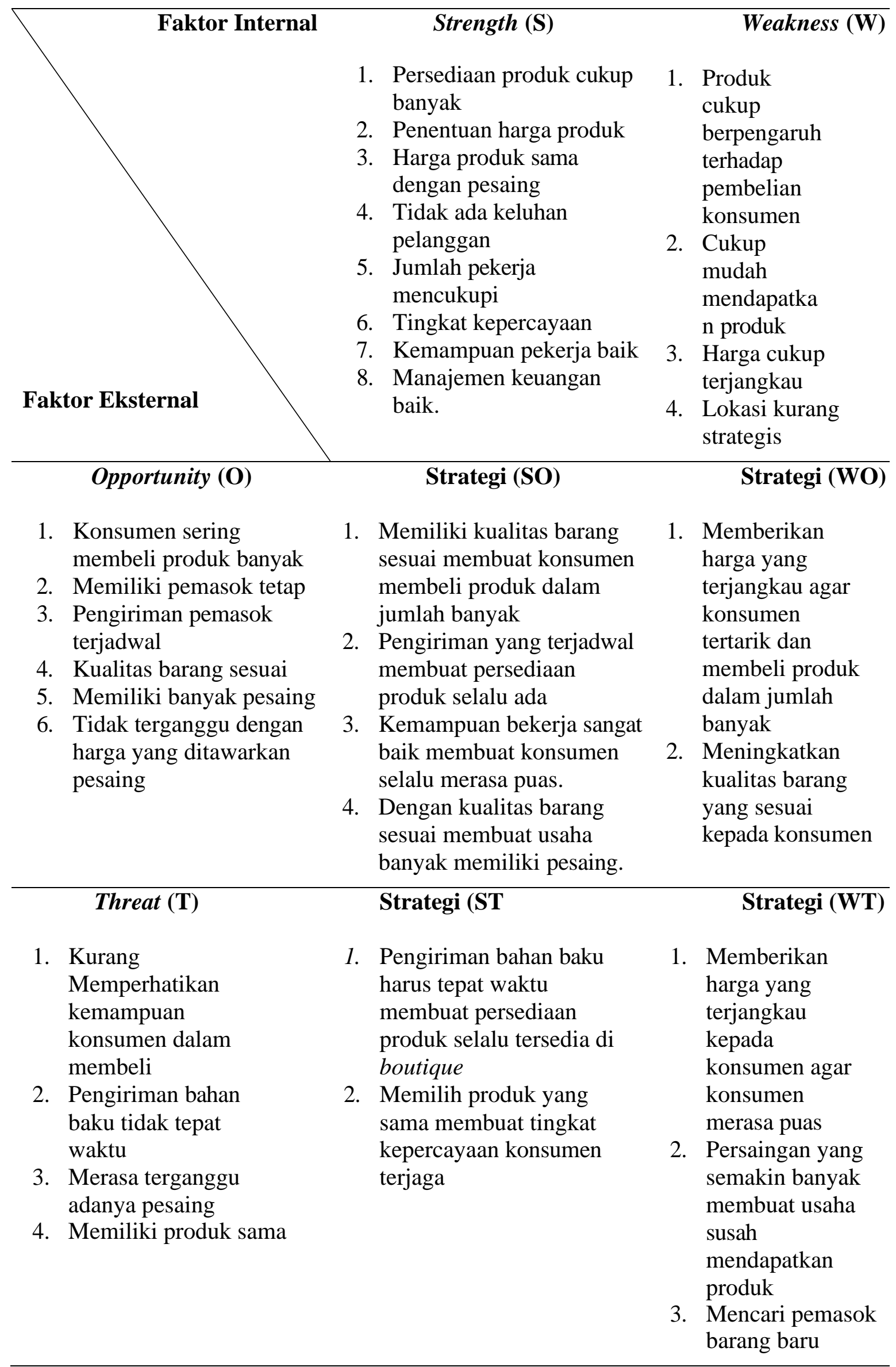

Tabel 5. Kombinasi Strategi Matrik SWOT 


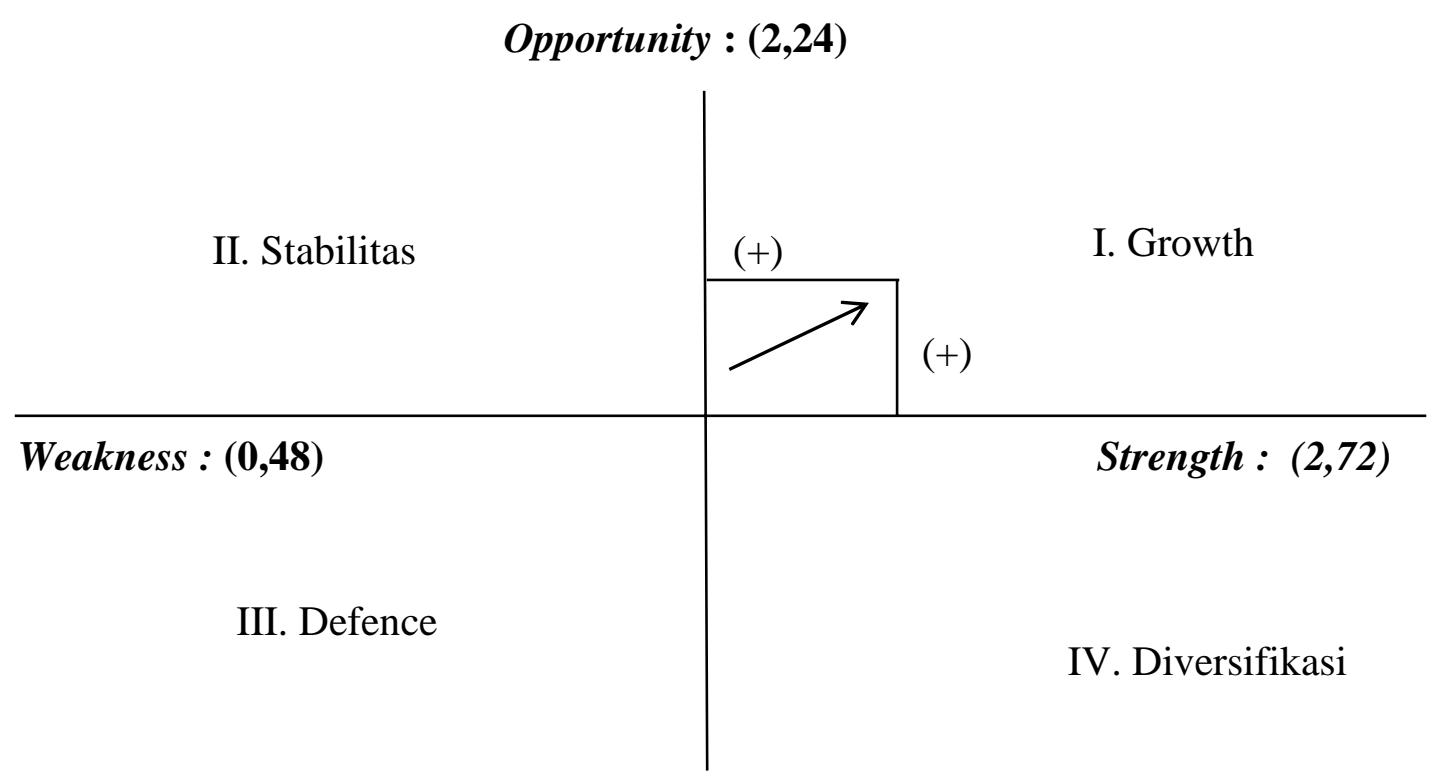

Threat: $(\mathbf{0 , 6 )}$

Gambar 1. Diagram Cartesius Analisis SWOT Love Shop Boutique di Bandar Lampung

Maka implementasi dari strategi SO Matrik SWOT tersebut adalah :

a. Memiliki kualitas barang sesuai membuat konsumen membeli produk dalam jumlah banyak.

b. Pengiriman yang terjadwal membuat persediaan produk selalu ada.

c. Kemampuan bekerja sangat baik membuat konsumen selalu merasa puas.

d. Dengan kualitas barang sesuai membuat usaha banyak memiliki pesaing.

\section{KESIMPULAN DAN SARAN}

\section{A. Kesimpulan}

Berdasarkan hasil analisis dan pembahasan pada penelitian ini, maka dapat diambil kesimpulan sebagai berikut : Berdasarkan hasil diagram cartesius analisis SWOT pada gambar 4.2, Love Shop Boutique berada di kuadran 1, dimana situasi ini sangat menguntungkan. Pada kuadran ini Love Shop Boutique memiliki kekuatan dan peluang, dari kekuatan sehingga dapat memanfatkan peluang yang ada. Strategi yang harus diterapkan dalam kondisi ini adalah mendukung kebijakan pertumbuhan agresif (Growth Oriented Strategy), yaitu : Kepemimpinan Biaya (Cost Leadership) : Pemilik dituntut untuk menguasai pangsa pasar yang relatif besar dan mempunyai keunggulan bersaing pada efesiensi biaya dan berusaha untuk menekankan pada upaya memproduksi produk atau menawarkan harga yang dijual dengan harga yang lebih rendah dibandingkan barang yang sejenis yang berada dalam satu kelompok industri tertentu dan menerapkan teknologi produksi yang tepat sehingga memiliki akses terhadap bahan baku yang lebih menguntungkan dibanding pesaing.b. Diferensiasi (Differentiation) : Dalam strategi ini, Love Shop Boutique berusaha untuk memproduksi dan memasarkan barang dengan karakteristik tertentu yang khas dan pada akhirnya mengakibatkan barang tersebut dianggap unik dan bahkan ekslusif oleh konsumen sehingga produk akan lebih laku di jual ke pada konsumen.c. Fokus (Focus): Pemilik memusatkan boutique atau mempertahankan ciri khas dari Love Shop Boutique sehingga bisa menjadi pembeda dengan pesaing yang ada, 
meningkatkan inovasi dari produk yang telah dimiliki dan membuat situasi senyaman mungkin sehingga konsumen kembali belanja di Love Shop Boutique dan selalu ramah terhadap konsumen yang datang. Berdasarkan analisis pada rumusan kombinasi strategi matrik SWOT yang dapat dilihat 4.6, startegi Love Shop Boutique yang efektif diperoleh startegi $\mathrm{SO}=4,96 \mathrm{WO}=2,72$ $\mathrm{ST}=3,32 \mathrm{WT}=1,08$. Adapun strategistrategi diatas sebagai berikut : Strategi (SO) : a. Memiliki kualitas barang sesuai membuat konsumen membeli produk dalam jumlah banyak, $b$. Pengiriman yang terjadwal membuat persediaan produk selalu ada, c. Kemampuan bekerja sangat baik membuat konsumen selalu merasa puas, d. Dengan kualitas barang sesuai membuat usaha banyak memiliki pesaing. 2. Strategi (WO) : a. Memberikan harga yang terjangkau agar konsumen tertarik dan membeli produk dalam jumlah banyak, b. Meningkatkan kualitas barang yang sesuai kepada konsumen. 3. Strategi (ST) : a. Pengiriman bahan baku harus tepat waktu membuat persediaan produk selalu tersedia di boutique, b. Memilih produk yang sama membuat tingkat kepercayaan konsumen terjaga. 4. Strategi (WT) : a. Memberikan harga yang terjangkau kepada konsumen agar konsumen merasa puas, b. Persaingan yang semakin banyak membuat usaha susah mendapatkan produk, c. Mencari pemasok barang baru.

\section{B. Saran}

Berdasarkan hasil penelitian serta kesimpulan diperoleh macam strategi yang dapat dilakukan untuk meningkatkan penjualan. Dalam menerapkan strategi-strategi tersebut sebaiknya pemilik Love Shop Boutique memperhatikan : Menambah varian produk agar konsumen tertarik untuk berbelanja di Love Shop Boutique dibandingkan boutique yang lain,
Memberikan promo dengan pembelian produk tertentu kepada setiap konsumen yang datang ke Love Shop Boutique dan Menampilkan produk yang menarik dari Love Shop Boutique melalui situs jejaring social seperti instagram, shoppe sehingga dapat menarik konsumen untuk berbelanja.

\section{DAFTAR PUSTAKA}

Aarker, David., 2013. Manajemen Pemasaran Strategis. Edisi 8. Jakarta: Salemba Empat. Abdul Rivai dan Darsono Prawinegoro. 2015 Manajemen Strategis. Jakarta : Mitra Wacana Media.

Abdullah, Thamrin dan Francis Tantri. 2016. Manajemen Pemasaran. Depok : PT Raja Grafindo Persada

Basu Swastha Dharmmesta. 2014. Manajemen Pemasaran. Yogyakarta : BPFE

Habiburrahman., Iskandar AA., Hendri

Dunan 2018 .Kewirausahaan Model

Strategi Pemberdayaan dan

Pengembangan UMKM. Bandar

Lampung : Pusaka Media

Habiburrahman., Iskandar., Hendri, Dunan., Haninun. 2019. Usaha Mikro Kecil Menengah (Model Strategi Pemberdayaan dan Pengembangan). Bandar Lampung : Pusaka Media

Ismail Solihin. 2012. Manajemen Strategik. Jakarta : Erlangga Joewono. 2012. Pengertian perencanaan edisi 12 halaman 3.

Kasmir dan Jakfar.2012.Studi Kelayakan Bisnis.(edisirevisi).Jakarta : Kencana Rangkuti, Freddy. 2013. Teknik Membedah Kasus Bisnis Analisis SWOT Cara

Perhitungan Bobot, Rating, dan OCAI. Jakarta. Penerbit PT. Gramedia Pustaka Utama.

--12014. Analisis SWOT: Teknik Membedah Kasus Bisnis. Jakarta. PT Gramedia Pustaka Utama -.2016. Analisis SWOT: 
Jurnal Manajemen dan Bisnis Vol. 11 No. 1 Oktober 2020: 53 - 62

Teknik Membedah Kasus Bisnis. Jakarta. PT Gramedia Pustaka Utama

Riswan dan Hendri Dunan 2019. Desain penelitian dan statistik multivariate.

Bandar Lampung : CV. Anugrah Utama Raharja

Robbins, P. Stephen, Mary Coulter. 2014. Management. Twelfth Edition.United States: Pearso Education Limited.

Sudaryono, 2015. Pengantar Bisnis-Teori dan Contoh Kasus. Yogyakarta: CV. Andi Offse 